\title{
Some thoughts on the reason for the lesser status of typology in the USA as opposed to Europe
}

\author{
ROBERT D. VAN VALIN, JR.
}

This article addresses the issue of the different status that typology has in American linguistics as opposed to European linguistics. The historical roots of the difference lie in both structural and generative linguistics, in the contrasts between post-Bloomfieldian structuralism in the US vs. Praguean structuralism in Europe, and in the extent of the influence of generative grammar on the two continents.

A significant aspect of the linguistics of the twentieth century was the struggle between description and theory, the conflict between the desire to capture the "structural genius" of languages (Sapir 1921) and the desire to capture what is universal in human language. This struggle played out rather differently in Europe and in the USA, and this contrast, I believe, is a telling factor in the current situation in which language typology is a much more significant and influential area of linguistics in Europe than it is in the USA.

Modern linguistics began in the USA as a reaction to the traditional grammar assumption that its Latin-based model was the appropriate framework for the description of all languages and to the evolutionary (and racist) interpretations of linguistic differences that were prevalent at the end of the nineteenth century (e.g., Powell 1880, 1891). Franz Boas laid out a framework for linguistic analysis which made no assumptions about the structure of the language to be investigated and which defined the descriptive categories to be used in terms of the structural properties of the languages themselves (Boas 1911). His most influential student, Edward Sapir, continued the development of this analytic framework in his 1921 book, Language, but unlike Boas, he was explicitly interested in crosslinguistic comparison, including a chapter on language typology which challenged some of Boas' assumptions about crosslinguistic variation (Sapir 1921: 128-129), while continuing the repudiation of the racist interpretations of linguistic differences (Sapir 1921: 130-132). After Sapir's and Boas' deaths in 1939 and 1941, respectively, the dominant form of structural linguistics in the USA rejected Boas' and Sapir's cognitive perspective, as well as Sapir's 
and Whorf's (Whorf 1945) typological insights, and embraced an extreme form of Boasian particularism, one which Boas himself might well have rejected. ${ }^{1}$ American structural linguistics, with its focus on describing languages, was potentially a natural intellectual environment in which the study of language typology could develop, but only at the very end of the era of structural linguistics in the USA did the study of language typology finally re-emerge, led by Joseph Greenberg (Greenberg 1963).

The intellectual environment within linguistics in the USA changed radically beginning in the late 1950s with the arrival of Chomskyan generative grammar. Chomsky $(1981: 4,7)$ summarizes this change succinctly:

The study of generative grammar in the modern sense [...] was marked by a significant shift in focus in the study of language. To put it briefly, the focus of attention was shifted from "language" to "grammar" [...]. We shift our focus from the language to the grammar represented in the mind/brain. The language now becomes an epiphenomenon; it is whatever is characterized by the rules of the grammar [...]. The grammar in a person's mind/brain is real; it is one of the real things in the world. The language (whatever that may be) is not [...].

The shift of focus from language (an obscure and I believe ultimately unintelligible notion) to grammar is essential if we are to proceed towards assimilating the study of language to the natural sciences.

Generative linguistics is not about language(s); it's about grammar(s). Chomsky's more recent formulation is in terms of an opposition between "E[xternal]language" (= "language" in the quote above) and "I[nternal]-language" (= grammar), but it is the same contrast.

This shift in focus was accompanied by a fundamental reorientation of linguistic theory from being descriptive (inductive) and instrumentalist methodologically to being deductive (explanatory) and non-instrumentalist. These changes had profound consequences, many of which are summarized by Chomsky (1965: 208-209) as follows:

A theory of language must state the principles interrelating its theoretical terms (e.g. "phoneme," "morpheme," "transformation," "Noun Phrase," "Subject") and ultimately must relate this system of concepts to potential empirical phenomena

1. The epitome of this is Joos' (1957: 96) famous comment: “Trubetzkoy phonology tried to explain everything from articulatory acoustics and a minimum set of phonological laws taken as essentially valid for all languages alike, flatly contradicting the American (Boas) tradition that languages could differ from each other without limit and in unpredictable ways [...]". This is a rejection both of explanatory theories in linguistics as well as crosslinguistic comparison. It is not at all obvious that Boas held the view the languages could vary in unlimited and unpredictable ways; see Boas (1911: 67-73). 
Table 1. Differences between (American) structural linguistics and generative linguistics

\begin{tabular}{lll}
\hline & Structural linguistics & Generative linguistics \\
\hline Object of inquiry & languages & grammars \\
$\begin{array}{l}\text { Definition of constructs } \\
\text { Result of inquiry }\end{array}$ & contrasts in data & role in grammars \\
& descriptions (theories) of & $\begin{array}{l}\text { theory of grammars = theory } \\
\text { languages = grammars }\end{array}$ \\
\hline
\end{tabular}

(to primary linguistic data) [...] [I]t seems to me that all significant structural notions will have to be characterized in terms of the previously defined notion "generative grammar" (whereas structural linguistics has assumed, in general, that the notion of "grammar" must be developed and explained in terms of previously defined notions such as "phoneme" and "morpheme"). That is, I am assuming that the basic notion to be defined is " $G$ is the most highly valued grammar of the language of which primary linguistic data $D$ constitutes a sample," where $D$ is represented in terms of the primitive notions of the theory; the phonemes, morphemes, transformations, etc., of the language are, then, the elements that play a specified role in the derivations and representations determined by $G$. If so, partial generative grammars will provide the only empirical data critical for evaluating a theory of the form of language.

Structural linguistics was about languages, and structuralist theory was concerned primarily with methodological issues regarding the identification and justification of the crucial analytic concepts, e.g., phoneme, morpheme. These analytic constructs were the building blocks of grammars, the descriptions (theories) of particular languages that were the output of structural analysis. The output of structural analysis is the starting point for generative analysis.

Theoretical constructs are defined in terms of their role in grammars, not directly in terms of facts about languages. ${ }^{2}$ Consequently, the data relevant to evaluating competing proposals are not facts about languages directly, but rather descriptions of those facts, i.e., grammars. This is why Chomsky (1965: 208-209) says "partial generative grammars will provide the only empirical data critical for evaluating a theory of the form of language". These differences are summarized in Table 1.

There was one more important feature of the Aspects model which is relevant to this discussion, namely the distinction between formal and substantive universals. Formal universals are universal properties of grammars, while

2. For example, Halle's (1959) argument against the phoneme was not an argument that phonemic-like groupings of sounds do not exist in the sound systems of languages; rather, it was an argument that a theory of grammar which contained representations of such groupings would be less highly valued than one which did not. 
substantive universals are properties of languages encompassing the range of variation found in specific languages. For example, the fact that phonological representations are constituted by feature matrices is a formal universal, which Chomsky termed a "linguistic universal". ${ }^{3}$ The set of possible phonological features which particular languages draw on is a substantive universal; not all languages utilize exactly the same set of phonological features. Only formal universals are of any theoretical significance. A further important property of formal universals is that their recognition and justification does not necessarily involve looking at a range of languages, as Chomsky (1965: 209) makes clear:

Study of a wide range of languages is only one of the ways to evaluate the hypothesis that some formal condition is a linguistic universal. Paradoxical as this may seem at first glance, considerations internal to a single language may provide significant support for the conclusion that some formal property should be attributed not to the theory of the particular language in question (its grammar) but rather to the general linguistic theory on which the particular grammar is based.

Thus, the discovery of formal universals need not be the result of crosslanguage comparisons.

The intellectual environment associated with classical transformation-generative grammar of the Aspects model was, therefore, distinctly inhospitable to the growth and development of typology in the USA. Typology is first and foremost about comparing languages, and languages are not the object of inquiry in generative grammar. Moreover, it further suffered from its association with the ancien régime and from the fact that the part of generative theory that it was most relevant to, substantive universals, was considered to be of no theoretical significance.

Accordingly, during the great expansion of linguistic study at universities in the USA during the 1960s and early 1970s, typology was left behind. Linguistics departments were primarily hiring syntacticians and phonologists, not typologists, and graduate students were concentrating on the former, not the latter. This began to change starting in the mid-1970s with the advent of Relational Grammar and functional approaches to linguistic theory, but by this time, the expansion of linguistics departments stopped, reducing hiring drastically.

The situation was very different in Europe, for a number of reasons. First, European structuralists never adopted the extreme particularism of their American colleagues. Second, typology has long been part of the mainstream there. Trubetzkoy's (1939) Grundzüge der Phonologie, denounced by Joos in Footnote 1 , had a strong crosslanguage comparative perspective, and this was a

3. It is worth noting that Chomsky has never, to my knowledge, used the term "language universals". This is unsurprising, given his point about generative linguistics being about grammar and not language. 
salient feature of Prague School work, including Jakobson's, as well. Third, and perhaps most important, there has been much greater theoretical diversity in Europe than in the USA, in both the structuralist and generative eras. Bloomfield and the post-Bloomfieldians dominated structural linguistics in the USA from the 1930s to the 1960s, just as Chomskyan linguistics has dominated since then. Bloomfield's work did not have nearly the impact in Europe that it had in the USA, and while Chomsky's work has been highly influential in Europe as elsewhere, other traditions have survived and flourished, offering alternatives not found in the USA. ${ }^{4}$ In particular, the typological tradition continued to develop from the 1920s to the 1970s, rather than having been blunted, as in the USA, first by the Bloomfieldian tradition and then by classical generative grammar.

Received: 17 December 2005

Heinrich-Heine-Universität, Düsseldorf

Received: 21 December 2006 University at Buffalo, The State University of

New York

Correspondence address: Allgemeine Sprachwissenschaft, Institut für Sprache und Information, Heinrich-Heine-Universität Düsseldorf, 40225 Düsseldorf, Germany; vanvalin@phil-fak. uni-duesseldorf.de

\section{References}

Boas, Franz (1911). Introduction. In Franz Boas (ed.), Handbook of American Indian Languages, Volume 1 (Bureau of American Ethnology Bulletin, 40-1), 1-83. Washington: Government Printing Office.

Chomsky, Noam (1965). Aspects of the Theory of Syntax. Cambridge, Mass.: MIT Press.

- (1981). On the representation of form and function. The Linguistic Review 1:3-40.

Greenberg, Joseph (ed.) (1963). Universals of Language. Cambridge, Mass.: MIT Press.

Halle, Morris (1959). The Sound Pattern of Russian. The Hague: Mouton.

Joos, Martin (ed.) (1957). Readings in Linguistics: The Development of Descriptive Linguistics in America since 1925. Washington: American Council of Learned Societies.

Powell, John Wesley (1880). Introduction to the Study of Indian Languages, with Words, Phrases and Sentences to be Collected. Washington: Government Printing Office.

- (1891). Indian linguistic families of America north of Mexico. Annual Report of the Bureau of [American] Ethnology 7: 7-142.

Sapir, Edward (1921). Language. New York: Harcourt, Brace \& Co.

Trubetzkoy, Nikolaj S. (1939). Grundzüge der Phonologie. Göttingen: Vandenhoeck \& Ruprecht.

Whorf, Benjamin Lee (1945). Grammatical categories. Language 21: 1-11.

4. This might be due in part to the different organization structure of linguistics at European universities as opposed to American universities. In the USA, linguistics is concentrated in linguistics departments, whereas in some European countries, e.g., Germany, there are few "general linguistics" departments comparable to those in the USA, and most linguists are in language-related units. Given this more diffuse structure, it is perhaps more difficult for one particular view to predominate. 